\title{
Hotelaria do Nordeste: no Espelho da Globalização
}

\author{
Maria das Graças de Menezes V. Paiva ${ }^{1}$ \\ Keila Brandão Cavalcanti ${ }^{2}$ \\ Tereza de Souza ${ }^{3}$
}

RESUMO: Análise da hotelaria nordestina, tendo em foco a tecnologia organizacional. Resgatam-se enfoques teóricos sobre tecnologia, incluindo autores preocupados com aspectos técnico-organizacionais além de sociopolíticos, bem como analisam-se dados secundários e primários. Destacam-se categorias de análise mais diretamente correlacionadas com a dinâmica da globalização e discutem-se as perspectivas do mercado e da qualidade total.

PALAVRAS-CHAVE: Hotelaria; globalização; tecnologia organizacional; perspectivas de mercado; qualidade total; Nordeste; Brasil.

ABSTRACT: This article analyses the technological organization of the northeastern Brazilian hotels. It emphasizes the analysis in correlation of the globalization and it discuss the market perspectives and the total quality. It presents theorical aspects about hotel technology based primary and secundary data.

KEY WORDS: Hotels; globalization; organization technology; market perspectives; total quality; Northeastern region; Brazil.

1. Bachare CEPEME/SUDENE

End. para corresp.: R a D. Joaquim de Almeida, 2.076, Bloco A 603, Morro Branco - 59050-140-Natal - RN-Brasil.

2. Socióloga. Mestre em Administração pela Universidade do Rio Grande do Norte (UFRN). Especialista em Turismo pelo PPGAJUFR

3. Economista. Doutora em Administração pela EAESP da Fundação Getúlio Vargas. 


\section{Reflexōes Preliminares}

Rattner (1980:11 - 4) já chamava a atenção para o fato de que as análises das inovações tecnológicas ora privilegiavam o enfoque sistêmico funcionalista da administração tecnológica, visando objetivos pragmáticos de melhoria das técnicas de gestão e aperfeiçoamento da tecnologia, ora procuravam interpretar cada setor econômico específico em face das condições histórico-estruturais em países de capitalismo tardio. Na compreensão que se tem, as duas tendências não são mutuamente excludentes.

Este ensaio tem por finalidade aprofundar uma questão surgida quando da elaboração do projeto de pesquisa Tecnologia Hoteleira: Organização do Processo de Trabalho e Relações de Trabalho dos Hotéis do Nordeste. ${ }^{4}$ Nesse projeto questionava-se como os hotéis de proprietários e grupos empresariais da região tinham conseguido absorver a tecnologia hoteleira e como eles se posicionariam no mercado com a chegada de grupos nacionais e internacionais, já que se admitia que o turismo regional ingressava numa etapa de internacionalização.

Em diferentes oportunidades ampliou-se essa questão inicial. Numa primeira aproximação comparou-se a lógica da gestão dos hotéis singulares (independentes) dos hotéis integrantes de redes. Diversas e fragmentadas eram as fontes de informações disponiveis, assim como várias foram as ocasiões em que se teve acesso a novas informações (eventos, levantamento de dados, estágios de alunos, conversas com técnicos, trabalhadores e empresários e leitura de matérias na imprensa). Outros questionamentos surgiram, até porque as percepções dos atores eram variadas, devido a interesses prevalecentes. Atingiu-se outro patamar de entendimento, que agora é compartilhado com os que têm acesso a este ensaio.

No momento, a compreensão da hotelaria da região Nordeste não pode ser abstraída do contexto do expansionismo do capital no turismo e especificamente na hotelaria - refletido nas modificações dos espaços econômicos -, uma vez que mudam rotas e destinações e realizam-se investimentos estatais em infra-estrutura receptiva e urbana, ao mesmo tempo em que desenraízam-se investimentos de grupos multinacionais e de instituições financeiras internacionais para a região. Essa dinâmica não se reproduz apenas em nível macro. Em nível micro ela determina novas formas de gestão intra-organizacional, acarretando inclusive transformações no mercado de trabalho, à medida que, ao mesmo tempo que incentiva a flexibilização do trabalho e a competitividade, acarreta desemprego.

$\mathrm{O}$ ideário de qualidade total é bem-ilustrativo do processo acima descrito. Ao ser transferido para a hotelaria na região nordestina e no País como um todo, esse ideário tem gerado controvérsias, em virtude das relações de trabalho que predominam na região.

4. Participaram dessa pesquisa os professores Maria das Graças de M. V. Paiva, Keila Brandāo Cavalcanti, Tereza de Souza as alunas da graduação em Administração Maria Luiza de F. M. Medeiros, Catarina da Silva Souza e Sandra Campos da Costa.
O objetivo deste artigo é discorrer sobre a hotelaria nordestina focalizando a tecnologia organizacional. Destacam-se especificamente categorias de análise mais diretamente correlacionadas com a dinâmica da globalização e discutem-se as perspectivas de mercado e a qualidade total.

Em termos teórico-metodológicos resgatam-se enfoques teóricos sobre tecnologia, incluindo autores mais ligados a uma preocupação com os aspectos técnico-organizacionais, além dos sociopolíticos, bem como analisam-se dados secundários (documentos, revistas e jornais) e primários (levantados em cerca de vinte hotéis localizados em Fortaleza, Natal, Recife e Salvador, selecionados dentre as demais capitais da região por apresentarem maior fluxo de turistas quando da elaboração do projeto).

$\mathrm{Na}$ verdade deu-se prioridade a uma análise teórica com a inferência de dados ilustrativos.

\section{Globalizaçāo no Turismo e Hotelaria}

\section{Internacionalização do Capital e Globalização da Economia}

O modo de produção capitalista tem como objetivo e mola propulsora a reprodução ampliada do capital. Desde seus primórdios, o capitalismo exibe duas tendências: ao mesmo tempo em que se afirma no seio da sua formação social de origem como dominante, caminha no sentido de projetar sua expansão além das suas fronteiras nacionais.

Essa dupla tendência caracteriza fases distintas da evolução do capitalismo. No estágio do capitalismo competitivo prevaleceu a exportação de mercadorias; no estágio monopolista, sobretudo no imperialismo, o aspecto predominante e determinante é a exportação de capitais.

O funcionamento do sistema capitalista sempre se desenvolveu no contexto internacional. No início a dinâmica capitalista recorria ao comércio exterior para o suprimento de matérias-primas e alimentos. Todavia, a concepção de intercâmbios comerciais entre Estados nacionais já não basta para compreender a realidade atual. Agora, o modo de produção capitalista evoluiu para um quadro totalmente novo, em que o processo de internacionalização da produção se sobrepõe ao intercâmbio internacional

A nova realidade - ressalta Ianni (1992:67) é a emergência e o desenvolvimento da sociedade global. Para Michalet descortina-se uma economia mundial:

os espaços econômicos nacionais não mais coincidem com os territórios politicos; os Estados-Naçōes deixaram de ser espaços fechados e a antiga ordem internacional foi subvertida (apud Ohlweiller, 1986:87). 
Assegura Ianni (1992:73) que o mundo não é apenas uma constelação de Estados nacionais, centrais e periféricos, arcaicos e modernos, agrários e industrializados, coloniais e associados, dependentes e interdependentes, ocidentais e orientais, reais e imaginários. Para esse autor, as nações transformaram-se em espaços, territórios ou elos da sociedade global.

De fato, o mundo vive transformações importantes, onde se articulam forças sem nenhuma ruptura com o sistema capitalista, mas recriando formas de existência desse sistema. $O$ eixo central das modificações expressa a reprodução ampliada do modo de produção capitalista, através da associação do processo de internacionalização do capital com o fenômeno da multinacionalização das empresas. O processo de internacionalização da produção, destaca Ohlweiller (1986:87), associa-se à multinacionalização das empresas. Os países industriais já não se limitam a simplesmente vender fora das suas fronteiras nacionais uma parte maior ou menor da produção interna. Há um deslocamento do seu aparelho produtivo, transferem-se indústrias inteiras dos seus espaços nacionais originais para as outras economias desenvolvidas ou, mais comumente, para as tradicionais regiões periféricas de capitalismo menos desenvolvido.

Ressalva ainda Ohlweiller (1986:88) que,

essas modalidades de transferência das atividades industriais são, para todos os efeitos, uma espécie de prolongamento do espaço econômico das formaçōes sociais de origem para além das fronteiras nacionais. Os suportes da internacionalização da produção são as chamadas empresas multinacionais.

Originariamente as empresas multinacionais foram vinculadas a setores industriais de caráter monopolista. Sua expansão acelerada a partir do pós II Guerra Mundial se irradiou para outros setoreseconômiços, notadamente o terciário (bancos, turismo, consultoria etc.).

E claro que o processo da multinacionalização de empresas não consistc um fato novo na vida dos países capitalistas desenvolvidos. Ele vem se desenvolvendo progressivamente a partir da segunda metade do século XIX, embora tenha se intensificado a partir dos anos 50 do século XX com os investimentos norteamericanos nas regiões atrasadas, preferencialmente na América Latina.

As implicações desse processo são de fundamental importância. Os capitais instalados nas economias "atrasadas" determinam, nas mesmas, rápidas e profun das transformações provocadas pela difusão das relações de produção especificamente capitalistas. Isso se realiza, coincidentemente, mediante a destruição das relações sociais tradicionais próprias daquelas formações sociais (Ohlweiller, 1986:92).

Nesse contexto, relações de trabalho e organizações de processos de trabalho se encontram imbricadas no eixo das transformações, que se estabeleceram a partir do processo de internacionalização do capital e das condições prevalescentes em cada formação social. Dai a necessidade de se refletir melhor a temática organiza- ção e relações de trabalho, no âmbito da atividade hoteleira, numa região em que recebeu incentivos estatais importantes para implantação de diversos planos urbano-turísticos, nos quais predominam equipamentos hoteleiros.

\section{Globalização no Turismoe na Hotelaria}

É relevante notar que o capitalismo atual tem como principal característica ainternacionalização do capital: o modo de produção capitalista se reproduz de uma forma específica através da exportação de capitais, estabelecendo uma nova configuração da economia mundial.

Essa etapa do capitalismo monopolista iniciada com o fim da II Guerra Mundial não significa inexistência de oportunidades para investimento nos países desenvolvidos. A massa de capitaisé deslocada para oExterior porque a lucratividade dos capitais exportados é maior.

O resultado desse processo no turismo fez da atividade um dos três itens que mais gera divisas no mundo. Atualmente o turismo divide essa posição com atividades tradicionais como o petróleo e a indústria automobilística, tendo atingido taxas de incremento da receita na ordem de $11,5 \%$ ao ano, no período 1975/1987 (Rabahy, 1990).

Reforçando essa posição do turismo, Acerenza (1990) assegura que a OrganizaçãoMundial de Turismo-OMT notificou que, em 1990, a receita mundial som o turismo atingiu US\$209.155 milhões, movimentando um fluxo de 403.578 pessoas, sendo responsável por um em cada dez empregos gerados.

Rabahy assinala que em 1991 o turismo internacional movimentou um fluxo de aproximadamente 450 milhões de pessoas, gerando divisas da ordem de US\$280 bilhões, significando $7 \%$ do volume das exportacões mundiais. Como a relação do turismo internacional versus turismo doméstioo é de um para dez, prevê-se que o total de turistas raquele ano foi de cinco bilhões de pessoas (apud Rejowski, 1993) e

estima-se que o movimento de recursos gerados pelo turismo internacional e doméstico chega a cerca de US\$2 trilhōes, representando $65 \%$ das exportaçōes mundiais (apud Rejowski, 1993)

O expansionismo do capital no turismo pode ser reavaliado quando se confrontam os dados compilados pela OMT e por vários estudiosos que procuram subsidiar decisões de mercado e/ou a intervenção do Estado, até porque os impactos do turismo transcendem a esfera econômico/economicista em geral predominante. A OMT admite que o turismo constitui uma das principais atividades econômicas em nivel global, devendo crescer ainda mais nos próximos anos, desde que seja mantida a tendência do período de 1980 a 1989 de 5 a $4 \%$ ao ano. No entanto, uma análise dos fluxos e das receitas engendradas pelas atividades das organizações turísticas mostra uma concentração em países hegemônicos, o que origina sérias 
expectativas para países como o Brasil e, em especial, para a região Nordeste do mesmo.

O turismo traduz perfeitamente a lógica do processo de expansão do capital e da conseqüente multinacionalização de empresas. Há uma centralização de fluxos e receitas em torno dos países desenvolvidos, que concentram cerca de $80 \%$ desses dois itens, conforme dados da OMT.

Por outro lado, esses países, através das empresas multinacionais, possuidoras de vários empreendimentos no ramo, promovem verdadeira integração vertical em âmbito internacional, de tal forma que se cria um circuito, começando pela operadora de viagens, passando pela companhia de aviação e culminando com a rede hoteleira. Tudo isso numa dimensão internacional, abrangendo vários países, formando-se, assim, uma extensa diversificação horizontal que configura os chamados conglomerados multinacionais.

Para se ter uma idéia mais concreta desse fenômeno da multinacionalização e do domínio norte-americano, o Quadro 1 mostra as maiores cadeias hoteleiras do mundo e sua capacidade instalada nos vários países.

QUADRO 1 - MAIORES REDES HOTELEIRAS DO MUNDO

\begin{tabular}{l|l|c|c}
\hline $\begin{array}{c}\text { Cadeias } \\
\text { Hoteleiras }\end{array}$ & Sede & $\begin{array}{c}\text { Hotéis } \\
\left(\mathbf{n}^{\circ}\right)\end{array}$ & $\begin{array}{c}\text { Unidades } \\
\text { Habitacionais }\left(\mathbf{n}^{\circ}\right)\end{array}$ \\
\hline Holiday Ins & EUA & 1.755 & 303.598 \\
Best Western & EUA & 2.761 & 207.299 \\
Sheraton & EUA & 418 & 107.966 \\
Friendship Inns & EUA & 1.080 & 78.500 \\
Ramada & EUA & 635 & 94.000 \\
Trusthouse Forte & INGLATERRA & 810 & 72.299 \\
Hilton Corporation & EUA & 203 & 71.804 \\
Federation Nationale & FRANÇA & 4.345 & 71.711 \\
Supranational & SUIÇA & 370 & 70.000 \\
Howard Johson & EUA & 521 & 59.000 \\
\hline TOTAL & - & 12.898 & 1.136 .177 \\
\hline
\end{tabular}

Fonte: Service World Intemational, 1982

Pode-se observar pelo Quadro 1 que, entre as dez maiores cadeias hoteleiras existentes no mundo, sete são de origem norte-americana, uma inglesa, uma francesa, e uma suíça, totalizando 12.898 hotéis e 1.136 .177 unidades habitacionais. $\mathrm{Na}$ verdade, esses números confirmam domínio das multinacionais de origem norte-americana, o que comprova a hegemonia americana no processo de internacionalização do capital na atualidade, na hotelaria.

Ainda com base em dados dos Service World International (apud Ignarra 1989), pode-se comparar a capacidade hoteleirade a

milhões de leitos hoteleiros e extra-hoteleiros existentes no mundo, 4 milhoes concentravam-se nos Estados Unidos/França, Itália, Alemanha Ocidental, Espanha, Inglaterra, Canadá, México e Brasil ocupavam as posições seguintes. Contudo, como já foi evidenciado, o movimento do capital gira em torno dos países que sediam as corporações das quais fazem parte as maiores redes hote

Ainda que os dados citados se refiram a 1982, esse contexto não teve grandes alteraç̃os em termos de descentralização, haja vista a centralização do capital na chamada etapa de globalização. As informações mais recentes acusam que as grandes redes hoteleiras gerenciam estratégia

definidos. Paiva (1995), com base em informações cıtadas na revısta especıalizada Hotelnews, destaca o exemplo da corporação ACCOR, de origem francesa, cujos grupos hoteleiros se voltam para segmentos bem-definidos - o Novotel, Ibis e Parthenon, assim como a cadeia canadense Four Seasons.

Essas redes hoteleiras priorizam sistemas de gestão que investem em pesquisa e capacitação de recursos humanos, o que as fortalecem no mercado. Segundo Kibedi, a automação agilizou alianças entre instituições financeiras, empresas de transporte e comunicações, operadoras e cadeias de hotéis ${ }^{5}$ (apud Paiva, 1995)

Quando se propõem investir em atividades turísticas em novas localidades, essas corporações realizam estudos criteriosos, inclusive avaliações de mercado que apontam para lugares que conjuguem criatividade e exotismo, sendo possíveis destinações os países africanos, asiáticos, a América do Sul e o Caribe.

Paiva (1995) faz alusão a algumas particularidades do mercado turístico para as próximas décadas, referenciando uma pesquisa da Associação Internacional de Hotelaria, que mostra a influência de vários fatores sobre o mercado internacional de turismo:

- o decréscimo das taxas de natalidade e elevação dos níveis de expectativa de vida;

- maior participação dos aposentados e das mulheres;

- emergência no mercado turístico dos países do Pacífico e Ásia Ocidental, notadamente do Japão e dos novos países em fase de Industrialização, dentre os quais o próprio Brasil;

- influência da glassnot nos fluxos e nas destinações turísticas;

- modificações de atitudes e estilos de vida.

\footnotetext{
5. Na época Georg

sediaca Georg Kibedi era presidente da Associação Mundial para a Fornaç̧ão Profissional Turistica - AMFORT, sediada em Madri.
} 
Há unanimidade de opinião sobre o crescimento do turismo e da hotelaria nos próximos anos no contexto da globalização, apesar de os autores que vêem com otimismo a globalização para o turismo colocarem em questionamento a precariedade do sistema de coleta e análise de dados a proliferação das atividades informais e a tendência a superestimar ou subes. timar a sua vertente econômica, o que resultou numa imprecisão generalizada sobre o conhecimento do mesmo (Nasbitt, 1994:118-9).

$\mathrm{Na}$ realidade essas contradições são muito sensiveis na região Nordeste como se procurou demonstrar em trabalhos anteriores (Cavalcanti \& Paiva, 1989).

\section{Trajetória da Hotelaria no Nordeste}

A instalação dos primeiros hotéis de maior porte no Nordeste sempre esteve vinculada à exploração de atividades econômicas agrícolas, comerciais e industriais. No entanto, a partir da década de 60 , a hotelaria regional passou a ser articulada com a intervenção do Estado na promoção do turismo, esta última ainda mais marcante nas décadas seguintes (70,80 e 90).

A partir de 1959, a industrialização era fomentada no Nordeste sob 0 patrocínio da Superintendência do Desenvolvimento do Nordeste - Sudene, mas poucos foram os grupos que conseguiram crescer e diversificar seus investimentos, aproveitando oportunidades que surgiam em decorrência da cxpansão e modificação da estrutura produtiva regional e nacional. Sobressaiu-se na hotelaria o Grupo Bezerra de Mello, que até 1943 concentrava seus investimentos no comércio de tecidos e indústria têxtil, e que a partir daquele ano iniciou-se na indústria açucareira e hoteleira (Cavalcanti, 1993:92; Hotéis, 1993).

De acordo com dados do Banco do Nordeste do Brasil (BNB), no período de 1960 a 1966 a hotelaria nordestina cresceu 4,3\%. Das empresas beneficiadas pel 0 Fundo de Investimentos do Nordeste - Finor, no periodo 1966-1977, cerca de 37 eram hotéis, sendo 14 localizados na Bahia, 8 em Pernambuco e 15 nos demais estados nordestinos (Andrade,1981:56).

A partir de 1964 aampliação de investimentos eminfra-estrutura, notadamente melhoria e abertura de estradas estaduais e municipais, pontes e viadutós, contribuil decisivamente para investimentos no setor de turismo no Nordeste, uma vez que integrou a região a todo o território nacional (Cavalcanti, 1993:92).

Após o II Plano Nacional de Desenvolvimento - II PND, o turismo no Nordeste ganhou atenção especial uma vez que a política urbana privilegiava a ocupação da orla marítima com vistas à exploração do turismo. A hotelaria fo particularmente incentivada integrando os chamados "planos urbano-turísticos" (Cavalcanti 1993:92)

Se as primeiras unidades hoteleiras implantadas no Nordeste até meadosda década de 70 serviam de suporte a atividades econômicas em expansão, a partir do II PND seriam associadas à vontade política de incentivar o turismo do Nordeste em todos os niveis governamentais.
Posiçāo do Mercado Turístico do Nordeste em face da internacionalizaçāo do Turismo e da Hotelaria

A "nova" configuração das forças envolvidas na globalização revela, dentre mudanças, a transposição do poder econômico da esfera política para a econômica sob o escudo do mercado livre, "o desdobramento das tecnologias mais eficientes para o capital, a perda dos paradigmas alternativos como ponto de cenpírica, além da desmobilização popular" (Coraggio, 1994:225).

Segundo Coraggio (1994:226) é fundamental na América Latina não "reconhecer e analisar os múltiplos processos que constituem e acompaapenas "reconização", mas também estabelecer estratégias, até certo ponto utópicas, e tentativas, inclusive alternativas econômicas.

O que representa esse movimento especificamente para o turismo do Nordeste? Como já foi destacado no início deste artigo, ocorrem mudanças no mercado internacional de turismo, ao mesmo tempo em que as organizações turísticas têm de ser competitivas, o que implica melhor capacitação de recursos turísticas têm de ser competitivas, o que implica melhor capas e destinações e são concretizados acordos comerciais entre organizações do ramo.

É relevante deixar claro que qualquer análise sobre o mercado de turismo internacional para o Nordeste não pode ser ilusória, mas, ao contrário, bastante realistica.

Como se sabe, apesar do turismo nacional ter entrado numa etapa de internacionalização, a participação do país nos fluxos e receitas internacionais vinha sendo continuamente pouco expressiva, embora tenha ocorrido uma reação de 1992 para 1993 em relação às viagens internacionais que cresceram 13\% (Carvalho \& Brito, 1994).

No Nordeste percebe-se que há certa desinformação tanto por parte dos órgãos governamentais ligados ao turismo quanto das associações de classe e grupos empresariais privados, isto sem considerar a força de trabalho alocada nas organizações do setor. Como sempre a política de turismoprivilegiou a regeneração do capital e não a reprodução da força de trabalho. Nesse momento, diante das modificações impostas pelo governo, os trabalhadores que integram a força de trabalho em turismo estão totalmente fragilizados.

Verifica-se que as mudanças são bruscas, ocorrendo controvérsias inclusive no que tange às informações disponiveis. As conseqüências das modificações no mercado turístico são comprovadas pelo empenho dos organismos internacionais vinculados ao turismo, comoa OMT, detentora de dados confiáveise influenciadora na implementação de políticas públicas que propõem o turismo como alternativa para países não-desenvolvidos, dentre eles os latino-americanos, numa ótica de desenvolvimento sustentável. Esta discussão acontece em conjunto com o Banco Interamericano de Desenvolvimento - BID, tendo culminađo com a decisão pela alocação de recursos para investimentos em infra-estrutura urbana e viária na região Nordeste, através do Programa de Ação para o Desenvolvimento do Turismo no Nordeste - Prodetur-NE 
A Comissão Nacional de Turismo notificou que existem 104 "projetos turísticos" em andamento no País, o que representará cerca de 22 mil aposentos. Esta informação foi veiculada pela Gazeta Mercantil (10/4/95) que transcreveu matéria publicada no The Economist apontando outras evidências sobre uma possível ampliação do turismo do ponto de vista econômico no Brasil - este passou a participar em 7,8\% no Produto Interno Bruto - PIB, sendo indiscutível a sua capacidade de geração de empregos. Entretanto, o referido artigo comenta os preços abusivos, as altas taxas de juros que retraem os investimentos e a ausência na demanda internacional dos norte-americanos e asiáticos.

A expansão do turismo internacional para o Nordeste vem sendo demons. trada por indicadores disponiveis nos órgãos de desenvolvimento, embora sejam mais estimativos e especulativos, o que não impede que sejam considerados. Fala. se que no período de 1990 a 1994 o fluxo internacional para a região aumentou dez vezes e que as receitas totais de turismo na região alcançaram US\$ 1 bilhão de dólares (Gazeta Mercantil, 10/4/95).

Enquanto o BID investe US\$ 800 milhões em infra-estrutura que beneficiará desde aeroportos até saneamento básico, o Banco Nacional de Desenvolvimento Econômico e Social - BNDES lançou um projeto de US\$ 3 bilhões para a região, inclusive financiamento de hotéis (Gazeta Mercantil, 10/4/95).

Realmente os dados levantados nos órgãos oficiais de turismo da região corroboram a veracidade dessas informações. No Quadro 2, discriminou-se a ofert dos hotéis classificados, ficando evidente que a mesma já se distancia dos dados disponíveis no último Anuário Estatístico da Embratur.

O posicionamento de Salvador e Recife em $6^{\circ}$ e $9^{\circ}$ lugar dentre as capitais brasileiras mais visitadas por turistas estrangeiros deve-se à inclusão dessas duas capitais nas rotas de vôos regulares e charters, a partir do início da década de 90

Em 1992 Salvador foi interligada a 15 cidades de outros países (Buenos Aires, Montevidéu, Miami, Amsterdã, Frankfurt, Munique, Düsseldorf, Paris Roma, Milão, Madri, Barcelona, Tenerife, Orlando e Nova York), totalizando, em julho de 1991, 26 vôos e em 1992, 44 (Silva, 1993:14).

Só em 1992 Natal passoua participar de roteirosinternacionais notadamente de italianos, que constituem $30 \%$ da demanda internacional, além de argentinos espanhóis e alemães. Nesse esforço de colocar Natal dentre os destinos internacionais, o governo do Estado participou em 1993 de quatro feiras internacionais n Europa e Argentina, realizou 14 eventos tipo workshops e famtours (viagens de familiarização), além de 8 campanhas promocionais (O Poti, 13/3/94)

No entanto, não existe um sistema de avaliação que demonstre a objetividade desses esforços promocionais realizados, devido à própria precariedade do estrutura institucional que trata do turismo nessa capital.

Os demais estados do Nordeste seguem uma sistemática conjunta já que integram a Comissão de Turismo Integrada do Nordeste - CTI-NE. Ocorrem também ações de marketing isoladas por parte de cada capital.

E ilustrativo o caso do Ceará que conseguiu abrir novos mercados, inclusive ampliou a demanda doméstica após a realização de uma novela de televisão, que alocou um volume considerável de recursos (Gazeta Mercantil, 10/4/95)

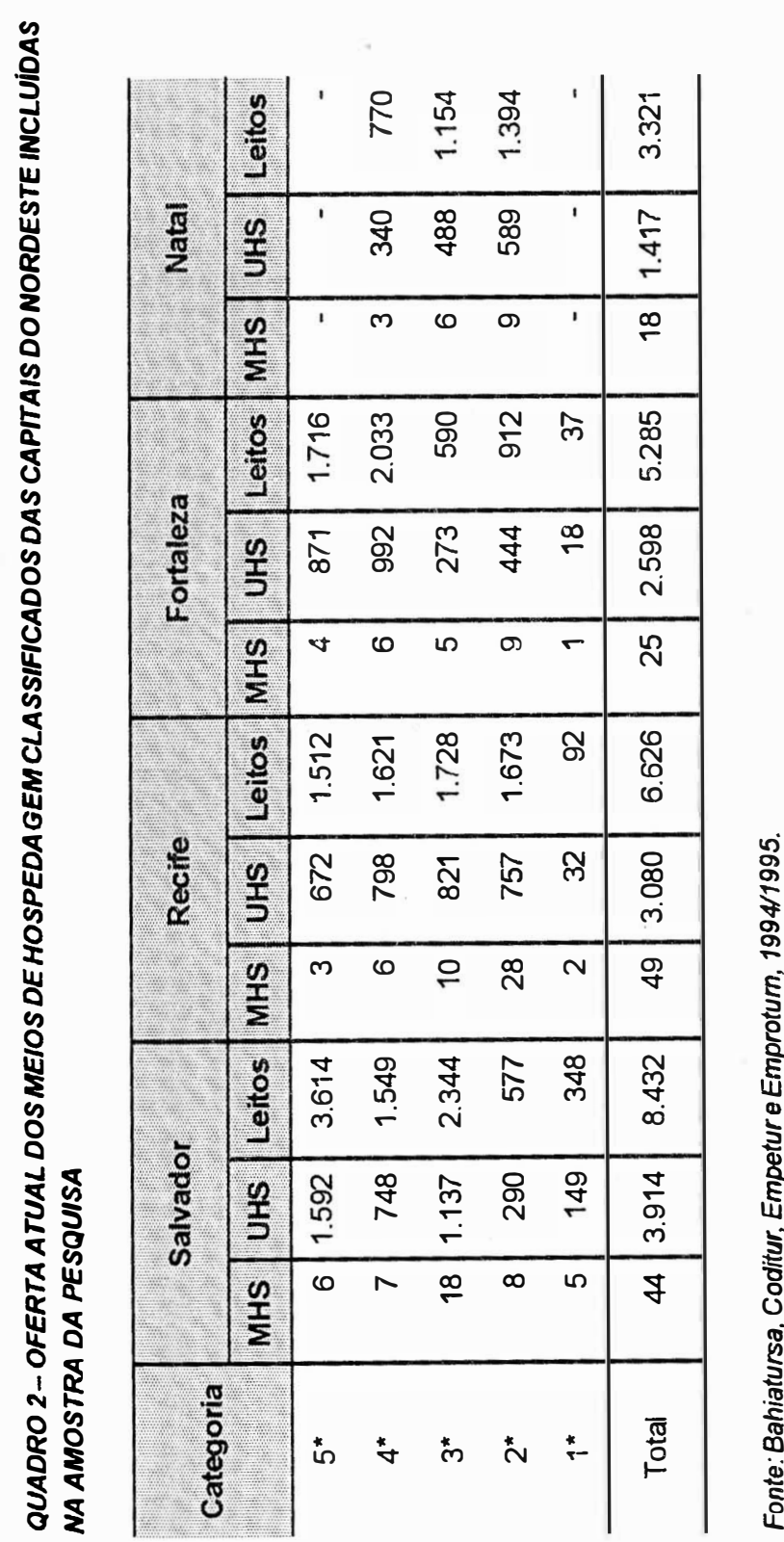


De modo geral cerca de $70 \%$ da demanda que possibilita a ocupação dos hotéis é doméstica, ficando em $30 \%$ a participação do fluxo internacional.

\section{Tecnologia Organizacional e Hotelaria}

Para Vargas (1983) tecnologia "não é máquina, nem técnica e não pode ser confundida com as forças produtivas ou com uma mercadoria qualquer", mas corresponde ao conhecimento formalizado, oriundo das técnicas existentes on disciplinas próprias, sendo orientado para um fïm prático e sujeito a critérios determinados pelas relações sociais e econômicas existentes.

Segundo Thiollent (1983:60-1), a tecnologia abrange não apenas o componente material de transformação fisica, como também o componente normativo que visa à redução dos problemas de produção ou de outros processos. $\mathrm{O}$ estudo do processo de trabalho conforme essa perspectiva abrange conhecimentos pluridisciplinares, um conteúdo teórico descritivo, além dos aspectos normativos, avaliativos ou prescritivos.

A divisão técnica do trabalho dentro das organizações compreende 0 instrumento fundamental de valorização do capital. Para intensificar o processode trabalho, a empresa moderna elimina obstáculos ao aumento da produtividade, através de formas de organização ou empregando inovações técnicas nos meios de produção, ou seja, a empresa utiliza técnicas de administração de recursos humanos tayloristas e fordistas quanto ao ritmo de produção, bem como estratégias de incentivo e motivação, ou então introduz inovações tecnológicas ao nível das máquinas e equipamentos.

Muitas vezes o trabalhador é solicitado a contribuir no aperfeiçoamento do processo de trabalho, o que de certa forma lhe restitui o saber fazer de que expropriado. Essa característica vai ser muito incisiva no setor de serviços e especificamente na hotelaria, embora seja uma característica de novas formas d gestão da força de trabalho.

O processo de trabalho em hotelaria baseia-se na prestação de serviços e qualificação de recursos humanos, sobretudo quando a qualidade total passa a se encarada como condição essencial para melhor colocação dos hotéis de empresários e/ou grupos empresariais autóctones no mercado.

Sábato (apud Figueiredo, 1994) procura caracterizar o que seria a tecnologia organizacional. Esta compreenderia um conjunto ordenado, organizado e atrelado de conhecimentos empregados na produção e comercialização de bens e serviços, abrangendo não somente conhecimentos provenientes das várias ciências, como conhecimentos empíricos que decorrem de observações, experiências e atitudes específicas ou da tradição oral ou escrita.

A percepção da tecnologia organizacional éfundamental para se internalizar as especificidades da tecnologia hoteleira das unidades estudadas.

Figueiredo (1994) distingue um sentido restrito e um sentido amplo da tecnologia. O sentido restrito compreenderia o know-how necessário para aplicar processos técnicos, pressupondo o uso de máquinas, equipamentos e manuais de procedimentos. No sentido amplo, aconteceria a incorporação de fatores complementares, tais como a qualificação de pessoas e a organização ("inserção da tecnologia no contexto organizacional").

Aos componentes hardware técnico e conhecimento brinware se adequa um arranjo organizacional que permite a combinação dos componentes mencionados e os meios gerenciados.

A diversidade dos tipos de estabelecimentos existentes, as filosofias e estratégias adotadas pelos empresários do setor e redes hoteleiras colocam em pauta o seguinte questionamento: existe uma tecnologia hoteleira ou são várias as tecnologias hoteleiras já que serviços e instalações são distintos nos vários estabelecimentos?

Estratégias para a Captação de Tecnologia Hoteleira no Brasil e no Nordeste

A história da hospedagem se confunde com a necessidade do viajante em ter um pouso que lhe permita "proteção, repouso, higiene, alimentação, privacidade e tranqüilidade", de maneira mais ou menos semelhante a sua própria residência. (Andrade,1992:164-5). Do surgimento das primeiras estalagens até os dias atuais nos quais a hotelaria se tornou um promissor setor econômico houve uma evolução, desde que foram incorporados serviços com a finalidade de tornar agradável a estada do hóspede (Santini, 1993:67). Kotler (1983) considera que a hotelaria integra o setor terciário da economia, uma vez que oferece serviços voltados para a satisfação e os desejos dos hóspedes.

A concepção contemporânea de hotelaria para Santini (1993) abrangeria tanto uma estrutura arquitetônica e física refersente ao uso dos seus vários espaços, como também um sistema administrativo que combine rapidez, eficiência e cortesia. O planejamento de um hotel não pode negligenciar sua arquitetura e distribuição dos espaços e usos, nem a concepção administrativa gerenciadora do processo de trabalho.

No Brasil, após a década de 60 , aconteceu uma verdadeira revolução na hotelaria em função da intervenção do Estado que adotou uma política de incentivos fiscais e financeiros. Pode-se afirmar que o órgão nacional de turismo foi além da promoção de investimentos, quando estabeleceu normas que de certa forma influenciaram também o processode trabalhoem hotelaria, anteriormente limitado aos parâmetros europeus dos hotéis implantados até os anos 60 .

Ferraz (1992:87), numa exaustiva análise da legislação referente à hotelaria, destaca 0 artigo $2^{\circ}$ da Lei n. $6.505 / 77$ que define atividades turísticas e respectivas condições de exercício e 0 artigo $1^{\circ}$ do Decreto n. 84.910/80 que regulamenta as empresas que exploram ou administram meios de hospedagem, além do artigo $2^{\circ}$ do mesmo decreto que os conceitua. Segundo esse autor, a condição do empreen- 
dimento ser tido como turistico ficava à mercê de avaliação da Embratur e de enquadramento na sua classificação em "tiplos, categorias de conforto, serviços e preços", conforme padrões definidos pelo Conselho Nacional de Turismo CNTUR (Lei n. 8.181/91).

A Embratur e suas entidades delegadas (órgãos estaduais de turismo), alèm dos órgãos repassadores de recursos, sempre pautaram a orientação para investido res quanto à construção e operacionalização na matriz de classificação que estabelece três grupos classificatórios - os construtivos (comuns e diferenciados), os equipamentos e instalações e os serviços (comuns e diferenciados).

Já a Resolução $n^{\circ}$ 09/83 conceitua empresa hoteleira e define as caracteris. ticas minimas dos meios de hospedagem, quais sejam os serviços obrigatórios oferecidos, as espécies de unidades habitacionais, normas quanto à fixação informação dos preços, utilização de símbolos de registro e classificação, uso da ficha nacional de registro de hóspede e boletim de hóspede para fins estatísticos.

Os aspectos normativos e prescritivos da legislação turística brasileira influenciaram tanto a concepção arquitetônica como o próprio processo de trabalho nos empreendimentos que surgiram, embora a tecnologia em hotelaria tenha recebido também a influência de outros condịcionantes. Contudo Ferraz (1992), no seu estudo, faz a ressalva que a legislação não foi seguida à risca, notadamente pelos hotéis já existentes ou em construção na época do primeiro regulamento, ou seja, em 1978. Outrossim, prevalecia a análise técnica de cada caso ou ainda ocorria a negligência quanto aos padrões das instalações e equipamentos, que terminavam por depender dos produtos disponiveis nos fornecedores.

Dentre outras influências sobre a tecnologia hoteleira, pode-se citar também tanto a chegada de grandes cadeias hoteleiras como a assimilação de conhecimentos empíricos por proprietários e empregados do setor, além das ações irradiadas pelo Serviço Nacional de Aprendizagem Comercial - Senac, através de seu Centro de Estudos de Administração Hoteleira - Ceatel.

Em 1981 o Senac, através do Ceatel, publicou uma coleção de manuais isolados e outros em convênio com a Organização Internacional do Trabalho-OI'T englobando métodos sobre organização do processo de trabalho na hotelaria visando simplificar e minimizar o exercício das tarefas nas áreas de administração geral (direção, compras, marketing, finanças), governança, alimentos e bebidas, cozinha, manutenção e administração de recursos humanos.

A metodologia consistia na definição dos departamentos, tarefas, perfis ocupacionais e perfis de competência. Verifíca-se na mesma a conotação taylorista com ênfase na racionalização do trabal ho, na departamentalização, no parcelamento em tarefas, pressupondo seleção e treinamento do trabalhador.

É indiscutível que se tratava de um esforço de adaptação do padrão internacional da divisão do trabalho em hotelaria, tendo sido escrito por tecnicos que cursaram a Escola de Hotelaria de Lausanne na Suiça e/ou treinados pela OIT.

\section{Qualidade Total em Hotelaria}

Do ponto de vista do empresariado da hotelaria parte dos problemas enfrentados concentra-se na entrada e permanência do empreendimento no mercado, de modo que seja mantida a ocupação dos aposentos disponíveis e viabilizado financeiramente o empreendimento. A consolidação do mercado aberto que é propiciada pela mundialização resgatou o ideário da qualidade total, que nos últimos anos passa a constituir um componente estratégico, também da gestão empresarial em hotelaria.

Todavia, a questão da qualidade total em hotelaria no Brasil não consistiu uma novidade, devido à natureza da atividade e o próprio empenho que a Embratur demonstrou desde a década de 70 . Através de convênios com órgãos estaduais de turismo, durante muitos anos fiscalizava-se o controle de qualidade dos meios de hospedagem do País. A assistência técnica da Embratur visava aperfeiçoar a qualidade do produto turístico brasileiro, mediante a orientação dos responsáveis pelos estabelecimentos e a verificação do cumprimento da legislação. Os órgãos relacionados com a saúde pública e relações de trabalho faziam, por sua vez, o controle no que se refere às condições de trabalho e higiene (por exemplo, de alimentos e instalações).

No entanto, o ressurgimento da qualidade total vem sendo mais marcante nos últimos anos em função da internacionalização da economia, baseado em métodos e técnicas científicas do trabalho que caracteriza a Gestão pela Qualidade Total (GQT).

Em relação à aplicabilidade da qualidade total na hotelaria, os estudos são raros. O conteúdo das análises disponiveis e dos seminários e cursos que são dados resulta das experiências dos analistas, expositores e/ou autores como consultores, professores, proprietários e/ou gerentes de hotéis. Em geral tenta-se fazer uma adaptação dos princípios gerais da gestão pela qualidade total à hotelaria, agregando conhecimentos empíricos de situações vivenciadas. Esses esforços podem ser encarados como avanços, uma vez que, como já foi destacado, a tecnologia organizacional incorpora conhecimentos empíricos

Nos estudos disponiveis identificaram-se duas tendências até certo ponto complementares, além da análise que procura integrar situações vividas que, se equacionadas, melhorariam os serviços em hotelaria. Neste último caso tem-se as análises de Castelli (1993), detentor de inquestionável know-how sobre hotelaria.

Uma primeira abordagem é aquela que se fundamenta nas normas ISO-9000. Ysochima (1994) afirına que em decorrência da internacionalização do mercado a hotelaria também foi atingida. Ele propõe a homogeneização dos serviços norteada por um padrão global de qualidade de acordo com as normas ISO 9000 , que representa um consenso dos diferentes países quanto à necessidade de adequação de produtos e serviços.

Uma segunda tendência sobre qualidade total na atividade turística é proposta por Maia (1993). Ele defende que as vantagens comparativas em turismo estão justamente em oferecer o diferencial. De acordo com este ponto de vista a 
qualidade da prestação de serviços em turismo deveria ter por base a "cultura regional/local" como inspiração e referência para a operacionalização e organização do serviço turístico de qualidade. Para ele o padrão de qualidade proposto pela ISO 9000, ao se fundamentar nos critérios de estandartização homogeneização, prejudica e inviabiliza o que os serviços turísticos teriam de mais característico.

Segundo Maia (1993) a tecnologia emergente, ao impor a massificação da produção exigida pela economia de escala, o incremento de consumo e ampliação do mercado, contribui para a diversificação e expansão do setor terciário, no qua! se situam os serviços turísticos e particularmente a hotelaria.

Os serviços turístico oferecidos em face dessa nova situação deveriam se pautar no perfil cultural e socioeconômico do meio ambiente onde são prestadose na capacitação de recursos humanos.

A percepção que se tem de qualidade total é de melhoria contínua de produtos, processos e pessoas da organização, atendendo expectativas de clientes que inclusive mudam continuamente. Persegue-se então um objeto móvel.

Poder-se-ia até fazer uma analogia entre a noção de qualidade total de Isochima, com os sistemas de administração a distância das redes e cadeia hoteleiras, e a posição de Maia que se aproxima mais dos hotéis de menor porte Contudo, dada à complexidade do que vem acontecendo no macro ambiente prefere-se admitir que esses dois enfoques são complementares.

\section{Consideraçōes Finais}

A dinâmica da mundialização está sempre a exigir das organizações a combinação de regras gerais quanto à gestão, abrangendo valores, princípios, reconhecimento e participação dos empregados e a busca de um padrão de qualidade que promova a cultura local. Esta constatação evidencia que as tendên. cias citadas não são mutuamente exclusivas.

Estabelecendo um paralelo com o contexto da hotelaria nordestina, tomando por referência os hotéis pesquisados, numa primeira aproximação tem-se que:

- a maior parte dos hotéis pesquisados valorizam a cultura nordestina, emboraessa preocupação seja maior nos hotéis integrantes das redes hoteleiras;

- muitos hotéis são administrados como se fossem casas;

- existem hotéis cujo layout não facilita o processo de trabalho, como também superestruturas fisicas que não foram acompanhadas da assimilação da tecnologia hoteleira;

- há serviços para todos os gostos e gostos para todos os serviços;

- a rotatividade de empregados inter-setorial, além de mostrar falta de estabilidade existente, bastante acentuada na hotelaria do Nordeste, termina por difundir informalmente procedimentos entre as organizações turísticas, por meio dos próprios empregados

qualidade total na hotelaria ainda fica reduzida ao discurso, quando não são melhoradas as relações de trabalho e as questọes que giram em torno da cidadania plena da sociedade da região.

Se da perspectiva do empresariado existem dificuldades quanto ao mercado, do ponto de vista do trabalhador a hotelaria até agora não conseguiu abrir outros caminhos nas relações de trabalho prevalecentes, oque impossibilita a concretização qualidade total, limitando-se a mesma, quando muito, aos procedimentos mecanicistas e aos apelos da propaganda, embora haja indiscutivelmente exceções no universo das empresas pesquisadas.

\section{Referências Bibliográficas}

ACERENZA, Miguel Angel. 1990. El turismo. Sua dinamica latinoamericana y sus limitaciones en el area de recurso humanos. In: Anais do II Seminário Latino-Americano da AMFORT. Turismo. Grande desafio dos anos 90 . São Paulo: AMFORT/ECA-USP, p. 12-36

A

do, capital e industrialização no Nordeste. Rio de Janeiro: Zahar.

Eestino Brasil. Novos caminhos para o turismo. Rio de Janeiro: AM Produç̄es.

.

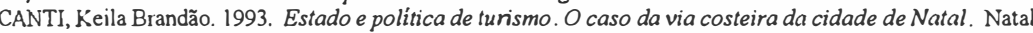
U.RN (Dissertação de Mestrado)

CAVAICANTI, Keila Brandão \& PAIVA, Maria das Graças de Menezes Venâncio. 1989. Repensando o crescimento do turismo no No

RAGGIO, José Luiz. 1994. A construção de uma economia popular como horizontes para cidades sem rumo. In RIBEIRO, L. C. de \& SANTOR JR. O. A. (org.). Globalização, fragmentação e reforma urbana. O futuro das cidades brasileiras na crise. Rio de Janeiro: Civilização Brasileira, p. $221-59$.

Tlä, Joandre Antônio. 1992. Regime juridico do turismo. Campinas: Papirus. HGUEREDO, Paulo César Negeiros de. 1994. Gestãode tecnologia emorganizaç̋̃es brasileiras. Na retada competitivida FLUURY da tavolagem em high-tech. Revista de Administração Pública. Rio de Janeiro, v. 28, n. 4, p. 163-85, out./dez. (9. FOLLA DE S. PAULO 1991 S̃̃o Paulo 24 out . Atlas.

FOLHA DE S PAULO 1995. São Paul, 7 jul, $2^{\circ}$ cad., p.

GAZETA MERCANTIL 1995 São Paulo 10 abr.

HOTEIS Othon. 50 anos 1993 (Revista comemorativa)

LNARRA, LuisRenato Evolução econômica da hotelaria brasileira: 1978-87. Boletim Técnico do SENAC. Rio de Janeiro, jan.-abr., 1989

Mul Octavivo. 1992. A sociedade global. Rio de Janeiro: Civilizaçào Brasileira

In emando. 1993. Qualidade dos serviçosno turismo receptivo. A contribuiçto dos rcarsos humasosn TMPOSIO LA'TINO-AMERICANO DE DOCE ESE INVESTIGADORESCIENTIFICOS DE TURISMO, KOTLR P D T ECA-USP/FTBa.

NASBITT Joph 1983. Marketing. $3^{3}$ ed. São Paulo: Allas.

OHLWE L 1994. O paradoxo global. Rio de Janeiro: Campus.

OPOTI LER, Otto Alcides. 1986. O capitalismo contemporíneo. Porto Alegre: Mercado Aberto.

OIT/SENAC. 13 março, p. 5. (Turismo - As novas fronteiras econômicas).

列 1980 Guia das profissões hoteleiras. Projeto capacitação profissional por módulos para a área de hospitalidade. São Paulo: SENAC (Documentos 1 a 5).

PAIVA, Maria das Gracas de Menezes Venâncio. 1995. Sociologia do turismo. São Paulo: Fapinus. 
RABAHY, Wilson Abrahảo. 1990. Planejamento turistico. Estudos econömicos e fundamentos econométricos. Şa Paulo: Loyola.

RATTNER, Henrique. 1980. Tecnologia e sociedade. Uma proposta para os paises subdesenvolvidos. São Paulo: Brasiliense.

REJOWSKI, Mirian 1993. Pesquisa acadêmica em Turismo no Brasil (1975-1992). Configuração e sistematizaçäo documental. São Paulo: ECA-USP. 2. v. Tese de Doutorado.

SAB.ATO, Jorge A. 1972. El comércio de tecnologia. Washington: OEA.

SANTINI, Rita de Cássia Giraldi. 1993. Reflexão sobre os espaços arquitetônicos dos hotéis sob a perspectiva do turismo de negócios. São Paulo. Turismo em Análise. São Paulo, v. 4, n. 22, nov., p. 67-80.

SILVA, Jorge Antônio Santos. 1993. Turismo em Salvador - 1992. Uma avaliação comparativa de desempenho. Turismo em Análise. São Paulo, v. 4, n. 2, maio, p. 35-45.

THIOLLENT, Michel. 1983. Problemas de metodologia. In: FLEURY, A. C. \& VARGAS, N. (org.). Orgarızaçäo do trabalho. Uma abordagem interdisciplinar. São Paulo: Atlas, p.54-83.

VARGAS, Nilton. 1983. A tecnologia é de Deus ou do diabo. Visões e conceitos de tecnologia. Ciência, tecnologia e desenvolvimento. Brasília: CNPq/UNESCO,1983.

YSOCHIMA. José Roberto. 1994. O turismo e as normas ISO série 9000 . Turismo em Análise. São Paulo, v. 5, n. 1, maio, p. 89-99.

\section{Recebido em 5/8/96}

Aprovado em 20/10/96 